\title{
A rare case of placenta percreta causing uterine rupture and massive haemoperitoneum in 2nd trimester: an obvious near miss
}

\section{Chirayu Parmar*, Mittal Parmar, Gayatri Desai}

Department of Gynecology, Kasturba Hospital, SEWA Rural, Jhagadi, Gujarat, India

Received: 30 December 2020

Accepted: 05 May 2021

\author{
*Correspondence: \\ Dr. Chirayu Parmar, \\ E-mail: drchirayu.parmar@gmail.com
}

Copyright: (c) the author(s), publisher and licensee Medip Academy. This is an open-access article distributed under the terms of the Creative Commons Attribution Non-Commercial License, which permits unrestricted non-commercial use, distribution, and reproduction in any medium, provided the original work is properly cited.

\begin{abstract}
Placenta accreta spectrum is very rarely encountered with ruptured uterus and is commonly seen in third trimester of pregnancy. Hereby, a case of placenta percreta with uterine rupture in second trimester of pregnancy is presented. 40 year old women with previous 2 LSCS presented in emergency department with ninteen weeks pregnancy and massive haemoperitoneum. Emergency laprotomy revealed uterine rupture alnong with placenta percreta for which obstetric hysterectomy was done. Although, a rare occurrence, obstetricians should consider patients placenta accreta spectrum in patients with previous surgeries presenting with haemoperitoneum and signs of hypovolemic shock in second trimester of pregnancy, considering the possibility of rupture at the site of placenta adherance.
\end{abstract}

Keywords: Placenta accreta, Rupture uterus, Placenta accreta syndrome, Haemoperitoneum

\section{INTRODUCTION}

Placenta accreta spectrum is a high-risk condition with fatal morbidities occuring due to abnormal invasion of placental tissue into the myometrium of uterus. Most favoured hypothesis suggests that there is abnormal decidualization in the area of uterine scar as a result of defect of the endometrial-myometrial interface, which allows abnormally deep placental anchoring villi and trophoblast infiltration. ${ }^{1}$ Rates of maternal death are increased because of severe life threatening haemorrhage.

Ruptured uterus is a very rare complication of placenta accreta spectrum with an incidence of 1 in 5000 pregnancies but can be catastrophic due to massive haemorrhage. ${ }^{2}$ We present here an intresting case of this severe life threatening complication in a previous 2 LSCS patient where morbidly adherent placenta led to uterine rupture in 2nd trimester of pregnancy requiring obstetric hysterectomy due to uncontrolled haemorrhage and severe hypovolemic shock.

\section{CASE REPORT}

A 40-year-old patient was referred to our labour room at 21st week of pregnancy for acute abdominal pain and massive haemoperitoneum. Patient had previous 2 LSCS with last done 3 years ago. She had taken MTP pills in the 2nd month of pregnancy followed by bleeding $\mathrm{p} / \mathrm{v}$ for 2 days. Patient had not taken any ANC visits and no USG scan was done. Patient presented in labour room with acute abdominal pain and signs of hypovolemic shock i.e pulse rate 140/m, BP 90/60, Hb $4.2 \mathrm{~g} / \mathrm{dl}$, HCT $15.9 \%$.

Patient was initially resuscitated with adequate fluid replacement and blood was sent for crossmatching. Patient was shifted urgently to USG which revealed single live intrauterine fetus with anterior low lying placenta covering the internal os. Placenta showed multiple inter-placental lacunae, thinning and hypervascularity at uterine serosa bladder interface suggestive of adherent placenta. USG also revealed sever ascites with mixed internal echogenicity. Abdominal tapping was done under USG guidance revealed frank blood. 
Patient collapsed on the USG table and was transferred to OT for urgent exploratory laprotomy. On entering the abdominal cavity approximately $4500 \mathrm{ml}$ of blood was drained. Approximately $5 \times 2 \mathrm{~cm}$ defect was noted on the uterus in lower uterine segment covered by placental tissue. Uterine scar was extended and fetus was delivered but the placental tissue cannot be seperated from myometrium. Decision for obstetric hysterectomy was taken in view of massive haemorrhage and adherent placenta. Patient was transfused 4 units of packed cells intraoperatively and 3 units thereafter. She was kept on ionotropes on 1st postoperative day and was discharged on 8th postoperative day in stable condition.

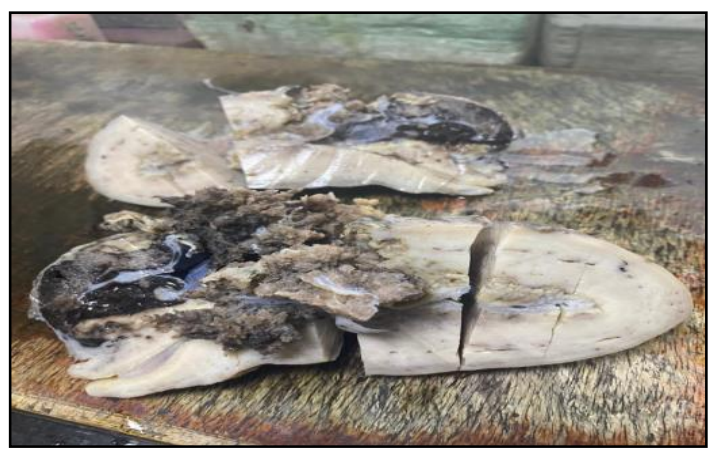

Figure 1: Specimen of uterus in cut section showing invasion of placenta into the myometrium.

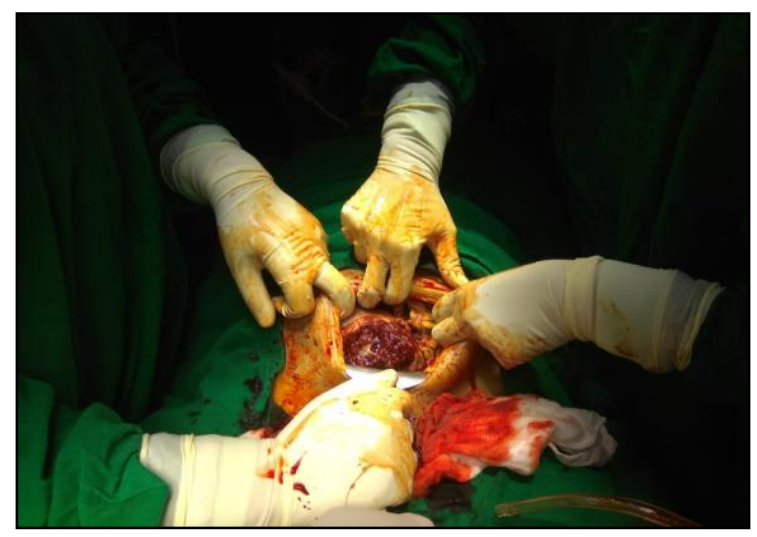

Figure 2: Intra operative image showing ruptured uterus with placental tissue protruding out.

Specimen sent for histopathological examination revealed presence of chorionic villi, trophoblastic tissue and decidua involving full thickness of uterine wall through the myometrium and adherent on extrnal surface of the uterus and cervix consistent with the diagnosis of placenta percreta.

\section{DISCUSSION}

The incidence of morbidly adherent placenta is very rare accounting for 1.7 in 10,000 pregnancies. However, incidence is higher in patients with previous cesearean sections, other previous uterine surgeries, IVF pregnancy and placenta praevia diagnosed in anteparum period. ${ }^{3}$ In most cases, placenta accreta is caused by a combination of factors and its occurrence is it unlikely to be attributed to a single factor. In our patient previous two caesarean section in addition to placenta praevia undiagnosed in the antepartum period explains the occurance of placenta accreta spectrum.

Spontaneous rupture in patients with placenta accreta spectrum is very rare especially in second trimester, but if occurs results in increased mortality in view of life threatening blood loss making it one of the most urgent obstetric complications.

In patients with high risk factors, ultrasound examination at bladder uterine interface for interruption and hypervascularity is highly sensitive. Presence of placental lacunae is next most useful sign. MRI can provide additional information. ${ }^{4}$ In our patient MRI evaluation was not possible in view of hypovolemic shock and unstable vitals.

Haemoperitoneum in pregnancy is unusual but fatal. The differential diagnosis for haemoperitoneum in pregnancy are ruptured ectopic pregnancy, uterine rupture due to placenta accrete, placenta increta, or previous cesarean section, rupture of corpus luteum, superficial uterine vessel rupture, HELLP syndrome. Other non-obstetric causes of haemoperitoneum are rare and include rupture of an spleenic rupture, arterial aneurysm, rupture of haemangioma or liver tumours. ${ }^{5}$ In our patient abdominal tapping done revealed frank blood which in combination with USG sign suggesting placenta accreta suggested the possibility of obstetric cause of haemorrhage necessitating exploratory laprotomy.

\section{CONCLUSION}

Therfore, it may be concluded that the consequences of undecteted placenta accreta can be catastrophic and it is important to maintain a high degree of suspicion in women with previous uterine surgeries. Early diagnosis with ultrasonography and doppler studies for the diagnosis of placental site along with MRI in doubtful cases becomes necessary so as to prevent life threatening complications like uterine rupture with massive haemoperitoneum.

Funding: No funding sources Conflict of interest: None declared

Ethical approval: Not required

\section{REFERENCES}

1. Cahill AG. Placenta Accreta Spectrum. Am J Obst Gynecol. 2019;6(2018):B2-16.

2. Jang DG. Placenta Percreta-Induced Uterine Rupture Diagnosed by Laparoscopy in the First Trimester. Int J Med Sci. 2011;8(5):424-27.

3. Fitzpatrick KE. Incidence and Risk Factors for Placenta Accreta/Increta/Percreta in the UK: A 
National Case-Control Study. PLoS ONE. 2012;7(12).

4. Comstock $\mathrm{CH}$, Bronsteen RA. The Antenatal Diagnosis of Placenta Accreta. BJOG: An Int J Obstet Gynaecol. 2014;121(2):171-82.

5. Kutty DN, Kanchana MP. A Rare Case of Haemoperitoneum in Pregnancy. J Clin Diagnos Res. 2016.
Cite this article as: Parmar C, Parmar M, Desai G. A rare case of placenta percreta causing uterine rupture and massive haemoperitoneum in 2 nd trimester: an obvious near miss. Int J Reprod Contracept Obstet Gynecol 2021;10:2495-7. 